\title{
Л.Б. Бадмаева
}

Институт монголоведения, буддологии и тибетологии СО РАН

\section{О синтаксических особенностях летописи Ц. Сахарова}

Аннотащия: Данная статья затрагивает проблему изучения языка письменных памятников бурят на старописьменном монгольском языке, созданных в XIX в. Статья посвящена изучению синтаксических особенностей баргузинской летописи Ц. Сахарова (1887), весьма ценного в информативном плане исторического сочинения. Синтаксис этой летописи характеризуется отсутствием длиннейших ССК, разнообразием предикативных форм: употребляются не только глагольные, но и именные, местоименные, наречные.

The paper is devoted to the problems of the language of the old written monuments of the Mongolian peoples, which were created in XIX century. The features of the syntactical structure of the Buryat historical annals" "Letopis' bargujinskiq buriyat" are considered in this paper. These historical annals' were written by the representative of the buryat feudal authority (taisha) C. Saqarov in Old Mongolian language in 1887. It is marked out, that there were not used the longest syntactical constructions - complicated syntactical complexes (CSC) in this text, which were revealed in Qori, Selenginsk buryat historical chronicles.

Ключевые слова: памятник старомонгольской письменности, летопись баргузинских бурят, сложный синтаксический комплекс (ССК), предикативные формы.

Old mongol literature, chronics of barguzin buryats, syntaxis, predicative forms.

УДК: 81'367.

Контактная информаичя: Улан-Удэ, ул. Сахьяновой, 6. ИМБТ СО РАН, отдел языкознания. Тел. (3012) 43-35 51. E-mail: lorabadm@mail.ru.

Как известно, духовную и материальную культуру монголоязычных народов, прежде всего, связывали с кочевым образом жизни номадов, и поэтому многие аспекты их письменной культуры долгое время оставались вне поля зрения исследователей. Между тем история письменности и книжной культуры монголов имеет многовековые традиции. Монгольские народы создали самобытную кочевую цивилизацию, одним из достижений и составной частью которой является письменность. В эпоху Чингисхана, в начале XIII в. среди монголов получила распространение письменность, заимствованная от уйгуров, так возник монгольский литературный язык, который уже в ту пору отличался от живых монгольских наречий.

Изучение истории письменности народов Центральной Азии показывает, что возникновение новой письменности было связано с образованием нового государства, что это было одним из основных проявлений идеи государственного суверенитета, например, Чингисхан, вступив на престол, провозгласил монгольскую письменность государственным языком своей империи. В связи с этим все государственные дела, официальные документы, дипломатические послания, записи бесед хана и князей с другими лицами, завещания составлялись на монгольском языке. В эпоху государства Их Монгол Улс много внимания уделялось развитию культуры, науки, разработке законодательных документов, созданию городов. 
Более того, в 1237 г. была разработана программа организации экзамена по письменности по всей империи, экзамен охватывал не только писарей. По итогам экзамена были отобраны 4030 человек, которые были приняты на государственную службу или же были назначены писарями. Была создана даже филологическая академия (bičig-ün küriyelen), в функцию которой входило составление, ведение летописей. Также в эту эпоху по приказу Угэдэя-хагана в Каракоруме были организованы монгольские школы, созданы секретный архив каганата, библиотека [Чулуунбаатар, 2000, с. 14].

Таким образом, истоки зарождения письменного наследия монгольских народов, в том числе и бурят, могут быть отнесены к данному периоду, так как согласно «Сокровенному сказанию монголов», предки бурят - племена хори и баргуты - относились к протомонгольским и имели близкую генеалогию с правящим у монголов родом борджигинов, которые, как и хори, произошли от Алан-гоа и Бодончара.

В монголоведной литературе существует несколько версий о времени возникновения старописьменного монгольского языка, о диалектной базе и о племени, который заимствовал его у древних уйгуров. Одну из гипотез, связывающей заимствование уйгурской письменности с найманами и кереитами, разделяли ученые Я. Шмидт, А.М. Позднеев, Б.Я. Владимирцов, Г.Д. Санжеев, Н.Н. Поппе и другие. Однако в последние годы появилась новая версия, согласно которой старомонгольская письменность впервые появилась у киданей, эту мысль поддерживают ученые Л. Лигети, Д. Кара, Чингэлтэй, Ц. Шагдар, Е.А. Кузьменков [Орловская, 1999, с. 4].

Собственно бурятские же сочинения на старомонгольской письменности стали появляться в XVIII в. в связи с консолидацией бурят в самостоятельную народность. Среди памятников старомонгольской письменности Бурятии летописи занимают исключительно важное место. Летописи являются не только ценными источниками исторической и культурологической информации, но и значимыми оригинальными литературными памятниками. Летописание монгольских народов было открытой системой, с одной стороны, сохраняющей и использующей традицию, с другой - пополняющейся новыми формами, оригинальными текстами. С художественной точки зрения летописи - синтез различных жанров, поскольку летописание интегрировало различные древние источники, письменные и устные, повествовательные и документальные.

Исследователи давно заметили, что духовные буддийские сочинения, заимствуемые бурятами из Монголии, переписывались без изменений, тогда как в светских произведениях наблюдались довольно заметные отклонения от классического монгольского языка. Об этом писали А.Д. Руднев, Б.Я. Владимирцов, Н.Н. Поппе и В.А. Казакевич. Это обстоятельство дало основание Б.Я. Владимирцову и его ученикам и последователям Г.Д. Санжееву и Т.А. Бертагаеву выдвинуть положение о том, что в Бурятии постепенно стал образовываться особый бурятский литературный диалект старомонгольского языка, названный Б.Я. Владимирцовым одним из «диалектических монгольских письменностей» [Владимирцов, 1929, с. 29].

Известный ученый Г.Н. Румянцев писал, что «буряты в течение одного столетия создали богатую историческую литературу, главным образом летописного характера. В своем творчестве бурятские авторы испытывали двойное влияние: с одной стороны, оказала воздействие старинная традиция монгольской историографии, в основном двух хроник, имевших в Бурятии большую известность - летопись Саган Сэцэна и “Алтан тобчи”; с другой стороны, знакомство с русской литературой отразилось на более критическом отношении к источникам» [Румянцев, 1960, с. 13].

Бурятские исторические хроники, являясь составной частью культурного наследия бурят, отражают многие стороны их общественной жизни, поэтому они 
заслуживают специального изучения. В эпоху тоталитарного режима данные памятники историографии Бурятии XVII-XIX вв., как и все литературное наследие бурят на старомонгольской письменности, долгое время находились в забвении, отодвинутые на задний план, более того, многие ценные памятники были варварски уничтожены.

В силу своего своеобразия бурятские летописи представляют интерес не только с исторической, культурологической точки зрения, но и филологической. Бурятские летописи содержат богатый и уникальный лингвистический материал, характеризующий специфику языка данного типа письменных памятников Бурятии XVIII-XIX вв.

На современном этапе лингвистическое источниковедение представляется одним из самых перспективных направлений в монголоведении, так как для воссоздания истории современных монгольских языков необходимы полные описания языка отдельных письменных памятников и выделение в них черт, унаследованных современным языком или со временем утраченных. Кроме того, научное описание языка письменных памятников важно не только для установления языковых связей во времени, но и для сравнительно-исторического исследования монгольских языков. Язык старописьменных памятников Бурятии отличается от современного бурятского языка не только по стилю, лексике, структуре предложения, но и в области морфологии, которая является наименее подвижной частью в системе языка. Сопоставление выявленных грамматических форм и их значений в языке летописных памятников с современным состоянием дает возможность выявить, в какой мере язык изменяется, и что остается неизменным на протяжении определенных исторических периодов времени. В частности, интересным представляется лингвистический материал, содержащийся в текстах баргузинских летописей XIX в., написанных на старописьменном монгольском языке.

Среди баргузинских бурят была довольно хорошо развита традиция летописания. Наиболее популярными являются следующие летописи. Летопись Цыдэбжаб Сахарова «Barүujin-u buriyad-nar-un erete urida dalai-yin qoyin-a-ača 1740

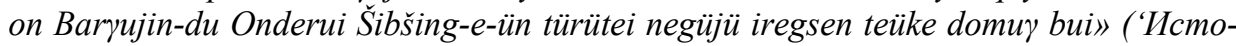
рия перекочевки в Баргузин в 1740 году баргузинских бурят с севера Байкала под предводительством Ондрея Шибшеева'), доведенная до 1880 г. [Румянцев, 1956], а также летопись Цыдэбжаб Сахарова «Летопись баргузинских бурят» (1887). [ЛББ, 1935].

Долгое время первая летопись считалась анонимной, Ж.С. Сажинов, сличив текст летописи с летописью Ц. Сахарова (1887), пришел к выводу, что эта летопись также принадлежит перу указанного автора [БЛ, 1995, с. 187].

Бурятский летописец Цыдэбжаб Сахаров родился 12 января 1839 г. в семье баргузинского тайши Сахара Хамнаева. Он приходится старшим сыном С. Хамнаева. По окончании в 1855 г. Верхнеудинского уездного училища с 16 лет в течение долгого времени работал учителем в Баргузинском приходском училище. Когда в 1882 г. умер его младший брат Цыренжаб Сахаров, который был главным тайшой баргузинских бурят, на эту должность в 1883 г. был избран Цыдэбжаб Сахаров. Кстати, их отец, Сахар Хамнаев, был утвержден в должности главного тайши в 1854 г.

Баргузинская летопись Ц. Сахарова (1887) была опубликована вместе с русским переводом, осуществленным самим же автором, в 1935 г. А.И. Востриковым и Н.Н. Поппе в Трудах Института востоковедения АН СССР [ЛББ, 1935]. В тексте летописи можно выделить две части: 1) представлена прошлая история баргузинских бурят; 2) хронологически последовательно изложены наиболее значительные факты и события из истории Баргузина. Содержание данной летописи перекликается с содержанием предыдущей баргузинской хроники «История перекочевки в Баргузин в 1740 году...» с некоторыми изменениями и дополнениями. 
Данная летопись Ц. Сахарова написана по просьбе чиновника Департамента иностранных вероисповеданий князя Э.Э. Ухтомского, прибывшего в Забайкалье по заданию Министерства внутренних дел с инспекцией на предмет исполнения «Положения о ламайском духовенстве в Восточной Сибири» 1853 года. Летописец Ц. Сахаров, будучи главным тайшой баргузинских бурят, отнесся к просьбе князя Э.Э. Ухтомского как к официальному заказу. Он представил подробное описание состояния вероисповедания баргузинских бурят, их образа жизни.

Как показали исследования языка бурятских летописей, произведения бурятских авторов характеризуются различными отклонениями от норм классического монгольского письменного языка [Владимирцов, 1929; Цыдендамбаев, 1972; Шагдаров, 1974; Доржиев, 1992; Бадмаева, 2005]. Между тем отклонения от норм классического монгольского письменного языка встречаются не только в памятниках бурятского летописания, но и в монгольских летописях, например, в монгольской летописи XVIII в. «Алтан тобчи» Мэргэн гэгэна. Исследователь данного памятника П. Балданжапов отмечает: «В целом летопись “Алтан тобчи” Мэргэн гэгэна написана на классическом монгольском письменном языке. Однако в ней встречаются отклонения от норм этого языка» [Балданжапов, 1970, с. 55]. Б.Я. Владимирцов по этому поводу отмечал: «Распространившись среди разных монгольских племен, говорящих на разных наречиях и диалектах, монгольский письменный язык начал до известной степени ассимилироваться с этими говорами. Влияние народной речи стало обнаруживаться и на правописании, потому что оно стало отражать фонетические особенности диалектов, и на морфологии, тоже менявшейся под влиянием заимствований из народных говоров, и на словаре. Классические нормы, нашедшие отражение главным образом в печатных изданиях, ничего не могли поделать со стихийным движением: письменный язык, начав шире обслуживать жизненные потребности монголов, стал приближаться к живому народному языку» [Владимирцов, 1929, с. 28].

Следует отметить, язык бурятских летописей имеет свои особенности и в синтаксическом плане. Как указывают монголисты, характерной особенностью синтаксиса бурятских летописей является наличие в них длиннейших конструкций, больших, чем сложное предложение. Будучи соединенными деепричастными и причастными формами, они, по выражению одного монгольского автора, тянутся как хвост змеи или бараньи тонкие кишки.

Г.Д. Санжеев вслед за А.А. Бобровниковым для обозначения таких длинных синтаксических конструкций старописьменного монгольского языка применял термин «период». Но в современной лингвистике под этим термином понимается сильно распространенное простое или многочленное сложное предложение, раскрывающее одну тему, со стороны интонации характеризующееся повышением и понижением тона. К тому же период отличается эмоционально-экспрессивной окраской, изяществом формы, поэтической структурой. Однако старомонгольские «периоды» не имеют подобного функционального назначения, да и по структуре они не похожи на эти периоды. По нашему мнению, из сверхфразовых единств (СФЕ) более близки к типичным синтаксическим конструкциям старомонгольского языка сложные синтаксические целые (ССЦ) - наиболее признанные единицы текста. Под текстом же, вслед за русистами, мы подразумеваем, во-первых, любое высказывание, состоящее из одного или нескольких предложений, имеющее законченный смысл, во-вторых, под ним разумеются такие произведения речетворчества, как повесть, роман, стихотворные произведения, газетная или журнальная статья, научная монография, документы различного рода, т.е. различаются два основных объекта текста: 1) ССЦ - текст в узком смысле слова, или микротекст; 2) целое речевое произведение - текст в широком смысле слова, или макротекст.

Иногда границы микро- и макротекста совпадают, когда целое речевое произведение состоит из одного СФЕ (газетная заметка, короткий рассказ, сообщение 
о погоде, объявление), поэтому не наблюдается различие термина «текст» в узком и широком смыслах слова [Москальская, 1981, с. 12-13].

Вместе с тем безоговорочно признать старомонгольские конструкции сложными синтаксическими целыми (ССЦ), какими они являются в русском языке, не представляется возможным. Дело в том, что данные конструкции состоят не из самостоятельных законченных предложений, а из зависимых предикативных единиц (ЗПЕ) неполного оформления и лишь с одним финитным сказуемым, которое придает высказыванию в целом формальную завершенность. После консультации с известным монголоведом Г.Ц. Пюрбеевым, мы пришли к выводу, что полипредикативные конструкции (ППК), употребляющиеся, в частности, в бурятских летописях, лучше всего назвать сложными синтаксическими комплексами (ССК) с монофинитным синтаксическим механизмом построения ${ }^{1}$. И, по нашему мнению, наиболее плодотворным представляется изучение подобных конструкций с позиции лингвистики текста.

Как известно, характерной особенностью синтаксиса хоринских и селенгинских летописей является наличие в них длиннейших конструкций - сложных синтаксических комплексов (ССК), состоящих из множества компонентов - зависимых предикативных единиц, с финитным сказуемым [Бадмаева, 2005, с. 150]. В них одной синтаксической конструкцией выражалось несколько самостоятельных мыслей. При таком построении речи в одной синтаксической конструкции информационную нагрузку несут глагольные слова, которые завершают отдельные мысли. Переход же к другой мысли совершается посредством причастий прошедшего времени в орудном и дательно-местном падежах, имен существительных с обобщенным значением в орудном падеже, а также посредством служебных слов-послелогов, союзов.

Следует подчеркнуть, что выражение мыслей посредством таких громоздких ССК, которые неискушенному читателю представляют известную трудность для правильного и быстрого восприятия текста, в баргузинских летописях отсутствует. Это и является характерной особенностью синтаксиса летописей Ц. Сахарова.

В старописьменном монгольском языке причастия в предикативной функции сопровождаются вспомогательными глаголами или связками. Это вспомогательный глагол а= 'быть' и его формы: атиі - изъявительная форма настоящего времени, аји - изъявительная форма настоящего времени заведомо известного действия, abai - изъявительная форма прошедшего времени, adjuүu, adji - изъявительная форма прошедшего времени неожиданного действия; вспомогательный глагол bö= ‘быть' и его формы bölüge, bile и т.д. Употреблялась также изолированная форма bui 'сущий', bui-ja 'вероятно, кажется' и buju 'есть' - изъявительная форма настоящего времени заведомо известного действия. В баргузинских же летописях все эти архаичные служебные глаголы употребляются очень редко, кроме того, причастные формы в роли сказуемых, как правило, выступают без них. Например,

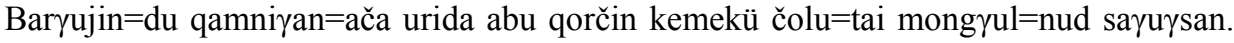
$\mathrm{Ede}=$ ner anu ene orun $=\mathrm{i}$ nigen ča $=\mathrm{tu}$ ros=iyar ejelegdemüi kemen dotur Kitad=un orun=a oruysan [ЛББ, 1935, c. 55]. 'По преданию в Баргузине до тунгусов жили монголы под названием аба-хорчины, а по другим сказаниям - монголы-баргуты, которые предвидя, что рано или поздно, этой страной завладеет Русь, ушли во внутрь Китая'.

Употребление причастия прошедшего времени в предикативной функции в рассматриваемой баргузинской летописи встречается очень часто, т.е. приобретает нормативный характер, например: 1829 on=du yalabnui tayiša Qamani Ceng-

${ }^{1}$ Термины ЗПЕ - зависимая предикативная единица, ППК - полипредикативная конструкция, монофинитная конструкция, бифинитная конструкция впервые введены лингвистами новосибирской синтаксической школы [см.: Черемисина, 1980; Скрибник, 1988; Ефремов, 1998; Скрибник, Даржаева, 2007 и др]. 
ker $=\ddot{n}$ üye $=$ dü engdeki buriyad $=$ nar mkanbuva blam $=a=y i$ $\gamma$ uyuju Selingge $=$ yin buri-

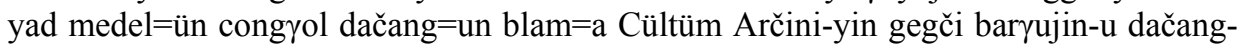

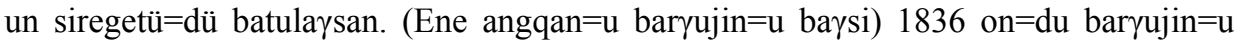
nituy=tu nögčigsen [ЛББ, 1935, с. 61] - 'в 1829 г. при главном тайше Хамнае Цанкирове по просьбе здешних бурят, был назначен (хамбо ламою) ширетуем Баргузинского дацана - лама Селенгинского бурятского ведомства из Цонгольского дацана Цултум Арзанов (который прежде был учителем в Баргузине) Он умер здесь в 1836 г.'.

Из других причастий в функции конечного сказуемого употребляются следующие формы: причастие многократное: Edenü yekengki oljun=yi tataqu aqalaүс̌i

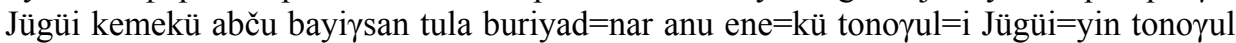
gejü kelčedeg: [Там же, с. 54] - ‘большей долей грабежа пользовался их начальник, которого звали Зугей; поэтому буряты эти грабежи называли «Зугеевскими грабежами»'.

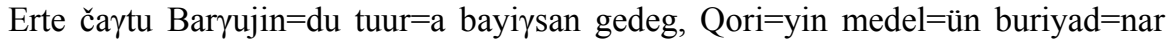
Baryujin ogrug=tu medel=tei bayizsan gedeg: [Там же, с. 58] - 'в прежние времена, говорят, в Баргузине существовал уездный город, тогда Баргузинскому округу подчинялись буряты Хоринского ведомства'. Здесь речь идет об известном историческом факте, что в период с 1783-1822 гг. Баргузин был уездным городом. В то время хоринские нойоны получали патенты на свое звание (зайсанов, шуленг, и т.д.) из Баргузинской канцелярии, а не из Нерчинской как было до этого. Sang=un alba bolun busu pobinosti=yi büküli jil=dü ribizi=yin düsid 3 tü 90 mönggü tölüdüg [Там же, с. 66]. 'Государственных податей и других повинностей круглым счетом взимается с ревизской души в год по 3 руб. 90 коп.' Как известно, под «ревизскими душами» в то время подразумевались люди, подлежавшие обложению подушной податью. Списки их составлялись во время ревизий.

Кроме причастия прошедшего времени и многократного причастия в качестве конечного сказуемого используется форма прошедшего времени изъявительного наклонения прошедшего времени с суффиксом =ba: например, Mön ralabnui tayiša bandada mkanbuva baryujin $=\mathrm{u}$ blam $=\mathrm{a}=\mathrm{nar}=\mathrm{un}$ dumda $=\mathrm{ača}$ budada $=\mathrm{a}=\mathrm{yin}$ sa-

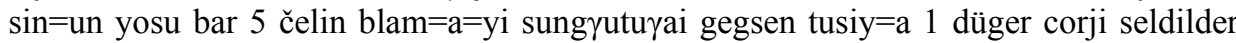

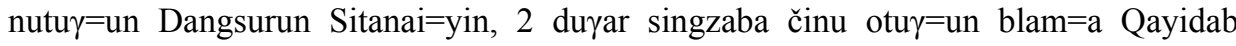

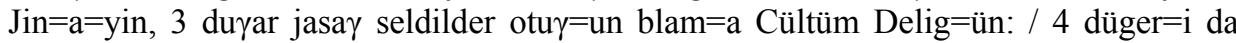

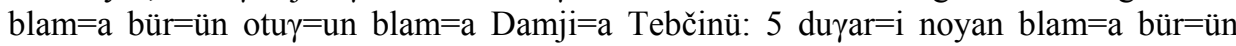

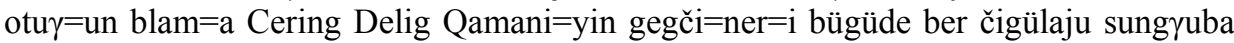
[Там же, с. 62-63]. 'В этом же году главный лама (в старомонгольском тексте описка - вм. blam=a 'лама' написано tayiša 'тайша'. - A.B.) бандида хамба Восточной Сибири предложил Баргузинскому дацану выбрать из среды баргузинских лам 5 непременных членов по дацану согласно правилам буддийской религии, вследствие чего советом дацана и с согласия всего бурятского общества были избраны: 1) цоржи лама сыньдыльдурского (сэнгэлдурского // һэнгэлдурского. Л.Б.) рода Данцаран Ситнаев, 2) шанзодба - лама шоноевского рода Хайдуб Зоноев, 3) засаг лама - лама сындыльдурского рода Султум Дылыков, 4) да лама - лама бурского рода Дамжи=а Тыбыженов, 5) нойон лама (нансо лама) - лама бурского рода Цырен-Дылыг Хамнаев’.

В этом предложении в качестве конечного сказуемого использован глагол прошедшего времени sungyuba. Иногда в качестве конечного предиката употребляется составной глагол со вспомогательным глаголом в качестве второго компонента: bügedeger budada $=\mathrm{a}=\mathrm{yin}$ šasin $=\mathrm{un}$ nomlal $=\mathrm{i}$ sonusuyad tegüneče qoiš $\mathrm{i}$ baryujin $=\mathrm{u}$ buriyad $=$ nar $=\mathrm{un}$ dumda budada $=\mathrm{a}=\mathrm{yin}$ šasin nara metü mandaqu bolba [Taм же, c. 59] - 'и целым обществом слушали проповеди буддийского учения и с этого времени среди баргузинских бурят, подобно солнцу, засверкал луч буддийского учения'. 
В языке баргузинской летописи довольно часто употребляется разговорная финитная форма belei // bele вм. стп.-монг. bölüge, например: Ene qada=ača $\gamma$ al $\gamma$ arču bayida $\gamma$ belei gelcedeg [Там же, с. 56]. 'Говорят, что с той горы исходил огонь // это была огнедышащая гора', ср. бур. перевод Харин гал гаража байдаг хада уулатай газар байтараа сүмэржэ, [БТБ, 1992, с. 163]; формы дицендиального глагола gekü: gejü вм. стп.-монг. kemen // kemejü: ene kü tonuүul=i Jügüi=yin tonurul gejü kelcedeg [ЛББ, 1935, с. 54] - 'эти события называли Зугеевскими грабежами', ср. совр. бур. «зүгэйн дээрэм» гэжэ нэрлэгдэдэг [БТБ, 1992, с. 162].

Тяготение Ц. Сахарова к народно-разговорному языку усматривается и в том, что он в качестве финитного сказуемого употребляет предельное деепричастие: ede buriyad=nar=tu il $\gamma$ aburi=tai bayiqu učir=i mong $\gamma u l$ ba mangji=yin orun=ača

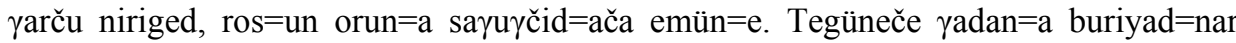

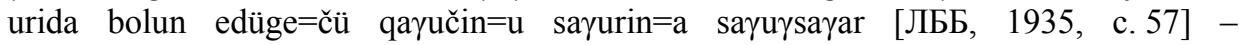
‘...впоследствии, вероятно, эти народы раздвоенные с появлением между Иркутском и Забайкальем настоящего моря Байкала, стали уже довольно резко отделяться от своих братьев монголо-бурят. Вот почему ныне будто находят между этими народами разницу и в разные эпохи будто бы переходившие между Монголией, Маньчжурией и Россией. Между тем настоящие буряты жили и живут как старые первобытные аборигены на своих местах'.

Изложение не совсем ясное как в старомонгольском оригинале, так и в переводе. Между тем лишь в переложении на современный бурятский язык Ж.С. Сажинова этот фрагмент звучит более определенно: Хоорондоо тогтоһон далайн хоёр талада ажаһуудаг аха дүу монгол яһатанай харилсаа барисаан таһаржа, дундаа тус бүриин илгабаритай болобо. Буряад зон Монгол ба Манжа оронһоо гаража ерээд, ородой орондо һуудаг буряадуудһаа гадна, эндэхи ёһото буряадууд анха урда түрэһэн гараһан дайдадаа һууһаaр гээщэ [БТБ, 1992, с. 163].

Довольно часто в качестве финитных сказуемых, как и в современном литературном бурятском языке, выступают именные формы, иногда в сопровождении

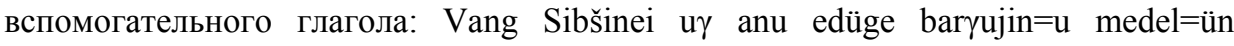
buriyad $=$ nar $=$ un $\gamma$ urim $=$ iyar Andreyeb=ten obu $\gamma=$ tai: Edeger $=\mathrm{e}$ dursa $\gamma$ da $\gamma \mathrm{san}=\mathrm{lu} \gamma=\mathrm{a}$

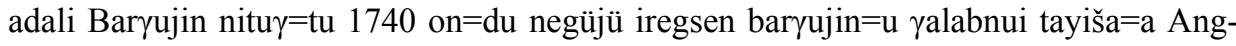

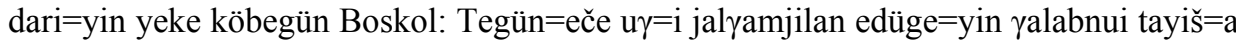
Cedeb Jib Saqarab=un 6 duүar üy=e=yin aqalaүči bui: [ЛББ, 1935, с. 53] - 'потомки князца Шевшея находятся в Баргузинском ведомстве и прозываются по бурятскому обычаю по отцу Андреевыми, по имени вышеупомянутого перекочевавшего из Анги в Баргузин в 1740 годах. В Баргузине был главным тайшей старший сын Андрея Боскол, от него до настоящего главного тайши Цыдэб Джаб Сахарова, происходящих от рода Андрея Шевшеева, наследственно управляют родами уже в шестом поколении'.

Отсутствие в баргузинской летописи длиннейших сложных синтаксических комплексов (ССК), расчлененное выражение мысли обусловили, таким образом, разнообразие сказуемых: употребляются не только глагольные, но и именные, местоименные, наречные.

Также следует отметить, что наряду с предикатами в рассматриваемой летописи достаточно четко выражаются и предметы мысли, субъекты и подлежащие. Заметно меньше случаев беспредметного и безличного изложения.

В целом, обозревая текст баргузинской летописи, следует заметить, что он написан с опорой на народно-разговорный язык, что язык данной летописи наиболее приближен к разговорному бурятскому языку. Языковой фон бурятских летописей представляет промежуточный письменный вариант между классическим монгольским письменным языком и разговорной формой бурятского языка.

Таким образом, филологическое исследование бурятских летописей, несомненно, имеет перспективы. Изучение языка летописных текстов будет способствовать решению ряда теоретических проблем, связанных с определением меха- 
низма взаимодействия традиций старомонгольской классической письменности и языка старописьменных памятников бурят. Исследователями подчеркивается, что развитие бурятского литературного языка будет более плодотворным, если будут освоены его истоки, изучены памятники всех жанров старой бурятской литературы. Поэтому дальнейшее изучение и переиздание памятников письменной культуры бурят, созданных на старомонгольской письменности, ныне приобретает актуальное звучание.

\section{Литература}

Бадмаева Л.Б. Язык бурятских летописей. Улан-Удэ, 2005.

Балданжапов П. Altan Tobči. Монгольская летопись XVIII в. Улан-Удэ, 1970. (БТБ)

Буряадай түүхэ бэшэгүүд / Сост. Ш.Б. Чимитдоржиев. Улаан-Үдэ, 1992.

Бурятские летописи / Сост. Ш.Б. Чимитдоржиев, Ц.П. Ванчикова (Пурбуева). Улан-Удэ, 1995. (БЛ)

Владимирцов Б.Я. Сравнительная грамматика монгольского письменного языка и халхаского наречия: Введение и фонетика. Л., 1929.

Востриков А.И., Поппе Н.Н. Летопись баргузинских бурят. Вып. І. Тексты и исследования // Труды Института востоковедения. Т. VIII. М.; Л., 1935. (ЛББ)

Доржиев Д-Н.Д. Старобурятский язык. Улан-Удэ, 1992.

Ефремов Н.Н. Полипредикативные конструкции в якутском языке. Новосибирск, 1998.

Москальская О.И. Грамматика текста. М., 1981.

Орловская М.Н. Язык монгольских текстов XIII-XIV вв. М., 1999.

Румянцев Г.Н. Баргузинские летописи. Улан-Удэ, 1956.

Румянцев Г.Н. Бурятские летописи как исторический источник // Труды БК НИИ СО АН СССР. Сер. Востоковедение. Вып. 3. Улан-Удэ, 1960.

Скрибник Е.К. Полипредикативные синтетические предложения в бурятском языке. Новосибирск, 1988.

Скрибник Е.К., Даржаева Н.Б. Полипредикативные конструкции обусловленности в бурятском языке. Улан-Удэ, 2007.

Цыдендамбаев Ц.Б. Бурятские исторические хроники и родословные. УланУдэ, 1972.

Черемисина М.И. О содержании понятия «предикативность» в синтаксисе сложного предложения // Полипредикативная конструкции и их морфологическая база. Новосибирск, 1980.

Чулуунбаатар Л. Письменность монгольских народов и ее культурноисторическое значение: Автореф. дис. ... канд. ист. наук. Улан-Удэ, 2000.

Шагдаров Л.Д. Функционально-стилистическая дифференциация бурятского литературного языка. Улан-Удэ, 1974. 